\title{
Genetic variability in multidrug-resistant Mycobacterium tuberculosis isolates from patients with pulmonary tuberculosis in North India
}

Ajay Vir Singh", Suman Singh, Anjali Yadav, Shweta Kushwah, Rajbala Yadav, Davuluri Kushma Sai and Devendra Singh Chauhan

\begin{abstract}
Background: Information on the genetic variability of drug resistant isolates of Mycobacterium tuberculosis is of paramount importance to understand transmission dynamics of disease and to improve TB control strategies. Despite of largest number of multidrug-resistant (MDR) tuberculosis cases $(1,30,000 ; 27 \%$ of the global burden), strains responsible for the expansion or development of drug-resistant Mycobacterium tuberculosis infections have been poorly characterized in India. Present study was aimed to investigate the genetic diversity in MDR isolates of Mycobacterium tuberculosis in North India.

Results: Spacer oligonucleotide typing (spoligotyping) was performed on 293 clinical MDR isolates of Mycobacterium tuberculosis recovered from cases of pulmonary tuberculosis from North India. Spoligotyping identified 74 distinct spoligotype patterns. Comparison with an international spoligotype database (spoldb4 database) showed that 240 (81.91\%) and 32 (10.92\%) strains displayed known and shared type patterns, while 21 (7.16\%) strains displayed unique spoligotype patterns. Among the phylogeographic lineages, lineage 3 (East AfricanIndian) was found most predominant lineage $(n=159,66.25 \%)$, followed by lineage 2 (East Asian; $n=34,14.16 \%$ ), lineage 1 (Indo-Oceanic; $n=30,12.50 \%$ ) and lineage 4 (Euro American; $n=17,7.08 \%$ ). Overall, CAS1_DEL (60.41\%; SITs $2585,26,2694,309,381,428,1401,141,25,1327)$ was found most pre-dominant spoligotype pattern followed by Beijing (14.16\%; SITs255, 260, 1941, 269) and EAI3_IND (5.00\%; SITs 298, 338, 11). The demographic and clinical characteristics were not found significantly associated with genotypic lineages of MDR-M.tuberculosis isolates recovered from pulmonary TB patients of North India.

(Continued on next page)
\end{abstract}

\footnotetext{
*Correspondence: ajayvir.s@icmr.gov.in; avsjalma@gmail.com

Department of Microbiology and Molecular Biology, ICMR-National JALMA Institute for Leprosy and Other Mycobacterial Diseases, Agra, Uttar Pradesh 282004, India
}

(C) The Author(s). 2021 Open Access This article is licensed under a Creative Commons Attribution 4.0 International License, which permits use, sharing, adaptation, distribution and reproduction in any medium or format, as long as you give appropriate credit to the original author(s) and the source, provide a link to the Creative Commons licence, and indicate if changes were made. The images or other third party material in this article are included in the article's Creative Commons licence, unless indicated otherwise in a credit line to the material. If material is not included in the article's Creative Commons licence and your intended use is not permitted by statutory regulation or exceeds the permitted use, you will need to obtain permission directly from the copyright holder. To view a copy of this licence, visit http://creativecommons.org/licenses/by/4.0/ The Creative Commons Public Domain Dedication waiver (http://creativecommons.org/publicdomain/zero/1.0/) applies to the data made available in this article, unless otherwise stated in a credit line to the data. 
(Continued from previous page)

Conclusions: Present study reveals high genetic diversity among the Mycobacterium tuberculosis isolates and highlights that SIT141/CAS1_Del followed by SIT26/ Beijing lineage is the most common spoligotype responsible for the development and transmission of MDR-TB in North India. The high presence of shared type and unique spoligotype patterns of MDR strains indicates epidemiological significance of locally evolved strains in ongoing transmission of MDR-TB within this community which needs to be further monitored using robust molecular tools with high discriminatory power.

Keywords: Spoligotyping, CAS1_DEL lineage, Mycobacterium tuberculosis, Multidrug resistant, North India

\section{Background}

Tuberculosis (TB) remains as an important infectious disease and public health concern worldwide. The emergence of drug resistance in M.tuberculosis strains has further worsened the situation and presents major hurdle for effective management of disease in most of developed and under developed countries of the world including India. Multidrug resistant (MDR) TB has been defined as resistance to isoniazid and rifampicin with or without any other first line anti-TB drugs. Additional resistance to fluoroquinolones and second-line injectables has been considered as extensively drug-resistant (XDR) TB. It has been estimated that about $3.4 \%$ of new cases and $18 \%$ of previously treated cases of $\mathrm{TB}$ in the world have MDR-TB or rifampicin-resistant TB [1]. According to the World Health Organization (WHO) estimates, globally 4,84,000 cases of MDR/ rifampicin resistant TB were emerged and about $6.2 \%$ of MDR-TB cases were identified as XDR-TB in 2018 [1].

India has the highest number of $\mathrm{TB}$ patients in the world and is accountable for about $27 \%$ of new TB cases developed globally [1]. As per the report of the "First National Anti-Tuberculosis Drug Resistance Survey" more than $6 \%$ of TB patients in India have MDR-TB [2]. Recently WHO reported that the number of MDR-TB in India is 99,000 and the country is accounting for about one-fourth of the global burden of MDR-TB [1]. Despite the huge number of drug resistant TB patients, limited information is available on the genomic diversity of drug resistant strains of M.tuberculosis circulating in the country [3-6]. The genotypic diversity of MDR/XDR-TB isolates of M.tuberculosis in India needs to be investigated to better understand the transmission dynamics of drug resistant $\mathrm{TB}$ and to strengthen the activities of TB control program in the country. The advent of molecular methods such as Spacer oligonucleotide genotyping (spoligotyping), restriction IS6110-based fingerprinting and Mycobacterial interspersed repetitive units-variable number of tandem repeats (MIRU-VNTRs) has provided new ways to determine the genetic diversity and epidemiology of M.tuberculosis within the study population $[7,8]$. Over the years, spoligotyping has been emerged as the most widely used molecular method for the investigation of genetic diversity and molecular epidemiology of $M$. tuberculosis in different countries including India [9-11]. Therefore, present study was aimed to identify predominant clades of spoligotypes responsible for the transmission and prevalence of MDR-TB in North India.

\section{Results}

\section{Details of patient's population and clinical MDR-TB} isolates

The detail of all the 293 clinical MDR-M.tuberculosis included in this study (according to patient gender, age, living conditions and clinical characteristics) is summarized in Table 1. Out of the 293 isolates, 105 (35.83\%) and $188(64.16 \%)$ isolates belonged to female and male, respectively. The median age of the female and male patients was 24 years (range 18-72 years) and 33 years (range: 18-85 years), respectively. Geographically, the majority of isolates were from Uttar Pradesh $(n=285$, 97.26\%) and adjoining states (Bihar and Rajasthan) of North India. The drug resistance pattern of MDR-TB isolates in this study is summarized in Table 2. Out of the 293 MDR-M.tuberculosis isolates in this study 125 (42.66\%) were resistant to all tested first line anti-TB drugs (Table 2).

Table 1 Clinical and socio-demographic characteristics of consecutively enrolled TB suspects

\begin{tabular}{llll}
\hline Variable & Category & Number & $\%$ \\
\hline Gender & Female & 105 & 35.83 \\
Age & Male & 188 & 64.16 \\
& $18-35$ & 198 & 67.57 \\
& $36-55$ & 68 & 23.20 \\
Living conditions & Above 55 & 27 & 9.21 \\
& Rural & 95 & 32.42 \\
Weight loss & Urban & 198 & 67.57 \\
& No & 45 & 15.35 \\
Previous history of TB treatment & Yes & 248 & 84.64 \\
& No & 99 & 33.78 \\
& Yes & 194 & 66.21 \\
\hline
\end{tabular}


Table 2 Drug resistance pattern of MDR-M.tuberculosis isolates $(n=293)$ and association with genotypic lineages

\begin{tabular}{|c|c|c|c|c|c|c|}
\hline \multirow[t]{2}{*}{ Drug resistance pattern } & \multirow{2}{*}{$\begin{array}{l}\text { No. of } \\
\text { strains } \\
\text { (\%) }\end{array}$} & \multicolumn{5}{|c|}{ No. of $M$. tuberculosis isolates in different genotypic lineages (\%) } \\
\hline & & $\begin{array}{l}\text { Lineage } 1 \\
\text { (Indo-Oceanic) }\end{array}$ & $\begin{array}{l}\text { Lineage } 2 \\
\text { (East Asian) }\end{array}$ & $\begin{array}{l}\text { Lineage } 3 \\
\text { (East African-Indian) }\end{array}$ & $\begin{array}{l}\text { Lineage } 4 \\
\text { (Euro-American) }\end{array}$ & Un-clustered \\
\hline MDR & $293(100)$ & $30(10.23)$ & $34(11.60)$ & $159(54.22)$ & $17(5.80)$ & $53(18.08)$ \\
\hline MDR+ Ethambutol & $157(53.58)$ & $12(7.64)$ & $23(14.64)$ & $85(54.14)$ & $11(7.00)$ & $26(16.56)$ \\
\hline MDR+ Streptomycin & $167(56.99)$ & $18(10.77)$ & $25(14.97)$ & $90(53.89)$ & $8(4.79)$ & $26(15.56)$ \\
\hline MDR+ Ethambutol + Streptomycin & $125(42.66)$ & $11(8.8)$ & $21(16.8)$ & $64(51.2)$ & $7(5.60)$ & $22(17.6)$ \\
\hline
\end{tabular}

\section{Genotypic variability among MDR M.tuberculosis isolates and distribution of lineages}

A total of 293 clinical isolates of MDR-M.tuberculosis were analysed using spoligotyping and 74 spoligotype patterns were identified. The lineage distribution of the M.tuberculosis isolates in this study is shown in Table 2. Out of the 293 MDR- M.tuberculosis isolates, 240 (81.91\%) isolates were clustered in 40 SITs in the SITV IT2 database (Table 3), while $32(10.92 \%)$ isolates were shown shared type patterns by a clade or SIT number in SITVIT2 database (Table 4) and 21 (7.16\%) isolates were identified with unique patterns (Table 5) making the total number of un-clustered isolates to be $53(18.08 \%)$.

Among the isolates of already defined spologotypes patterns $(n=240)$, East African-Indian was found to be most common lineage $(n=159,66.25 \%)$ followed by East Asian $(n=34,14.16 \%)$, Indo-Oceanic $(n=30,12.50 \%)$ and Euro-American lineage $(n=17,7.08 \%)$ in North India (Table 3). The majority of isolates belonged to CAS1_DEL $(n=145,60.41 \%$; SITs $2585,26,2694,309$, $381,428,1401,141,25,1327)$ followed by Beijing $(n=$ 34, 14.16\%; SITs255, 260, 1941, 269) and EAI3_IND $(n=12,5.00 \%$; SITs $298,338,11)$ sub-lineages. The other minor sub-lineages includes MANU2 $(n=10$, $4.16 \%)$, MANU1 $(n=4,1.66 \%)$, MANU3 $(n=1,0.41 \%)$, $\mathrm{T} 1(n=10,4.16 \%), \mathrm{T} 2(n=1,0.41 \%), \mathrm{T} 5(n=1,0.41 \%), \mathrm{CAS}$ $(n=12,5.00 \%), \operatorname{CAS} 2(n=2,0.83 \%), \mathrm{X} 1(n=2,0.83 \%), \mathrm{H} 1$ $(n=1,0.41 \%)$, EAI16_BGD1 $(n=1,0.41 \%)$, LAM2 $(n=1$, $0.41 \%)$ and LAM9 $(n=1,0.41 \%)$ in present study (Table 3). The SIT141 and SIT26 of the CAS1/Del sublineage and SIT1of the Beijing sub-lineage were found predominant SITs in present study, all together accounting for $60.41 \%(145 / 240)$ of the clustered MDR-M. tuberculosis isolates (Table 3).

The isolates with a pre-existing shared type pattern $(n=32)$ hence were labelled as 'orphan', belonged to 15 distinct patterns of spoligotype (Table 4). Out of the 32 isolates, $23(71.8 \%)$ were matched with a pre-existing SIT or clade in the SITVIT2 database while 9 isolates were matched with pre-existing 'Orphan' SIT and unknown clade pattern (Table 4). The isolates with unique spoligotype patterns $(n=21)$ were further analyzed to identify their most probable families using the SpotClust tool (Table 5). Five most probable families were recognized that included EAI5 with 9 (42.85\%) isolates, CAS with 7 (33.33\%) isolates, FAMILY-33 with $2(9.52 \%)$ isolates, EAI3 with $2(9.52 \%)$, and T2 with 1 $(4.76 \%)$ isolates.

\section{Association of MDR-M. tuberculosis lineages with clinical and epidemiological features of the patients}

The lineages of MDR-M.tuberculosis isolates were not found to be significantly associated with clinical and epidemiological features of the study population (Table 6). The clustered isolates were also not found to be significantly associated with clinical/epidemiological features of the patients (Table 7). The strains of predominant spoligo-type lineage (East African-Indian Lineage 3) was found higher in patients of male gender $(n=105$, $66.03 \%)$, young age (18-35 years) group $(n=109$, $68.55 \%)$, residents of rural areas $(n=63,39.62 \%)$ and with the history of previous TB treatment $(n=110$, $69.18 \%$ ) as compared to other spoligotype lineages; but the effect was not statistically significant (Table 8).

\section{Discussion}

Despite the largest number of MDR-TB patients $(99,000$ cases; $27 \%$ of global cases), less is known about the genetic biodiversity of MDR-M.tuberculosis strains in India. Most of the studies done so far either explored only the circulating genotypes of $M$. tuberculosis or included less number of MDR-M.tuberculosis isolates in the country $[3-6,12,13]$. To our knowledge, present study includes largest number of clinical MDR M.tuberculosis isolates $(n=293)$ to describe the predominant lineages and sublineages circulating in pulmonary MDR-TB patients in North India. In present study, high genotypic diversity (74 spoligotype patterns) was observed and we found that majority (81.91\%) of MDR-isolates were clustered into 40 spoligotype international types (SITs) in the SITVIT2 database. Similarly, Diriba et al., [14] investigated genetic diversity in MDR M.tuberculosis isolates in Ethiopia and identified 43 spoligotype patterns and high proportion of clustering (86.0\%) in MDR-TB isolates. In India, Desikan et al., [15] investigated the genetic diversity of M. tuebrculosis in TB patients from central India and reported the clustering of $70.3 \%$ isolates into 25 SITs. Chawla et al., [5] reported the clustering of $51.35 \%$ 
Table 3 Genetic diversity of MDR-Mycobacterium tuberculosis isolates recovered from pulmonary TB patients in North India showed pre-existing type pattern $(n=240 / 293)$ in the SITVIT2 database

\begin{tabular}{|c|c|c|c|c|c|c|}
\hline Lineage & Clade/Sublineage & SIT No & Octal code & Spoligotype Pattern & $\begin{array}{c}\text { No. of MDR isolate } \\
(\%)\end{array}$ & $\begin{array}{l}\text { Total number of } \\
\text { isolates }(\%)\end{array}$ \\
\hline \multirow{8}{*}{$\begin{array}{l}\text { Lineage } 1 \\
\text { (Indo- } \\
\text { Oceanic) }\end{array}$} & \multirow[t]{3}{*}{ EAI3_IND } & SIT298 & 477767777413071 & I.. & $5(2.08)$ & \multirow[t]{8}{*}{$30(12.50)$} \\
\hline & & SIT338 & 077777777413071 & 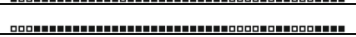 & $1(0.41)$ & \\
\hline & & SIT11 & 477777777413071 & 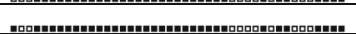 & $6(2.50)$ & \\
\hline & EAI5 & SIT458 & 7777777777403771 & 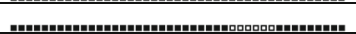 & $2(0.83)$ & \\
\hline & EAI16_BGD1 & SIT1970 & 777776757413771 & 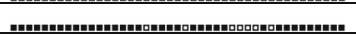 & $1(0.41)$ & \\
\hline & MANU1 & SIT100 & 777777777773771 & 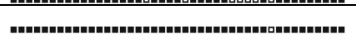 & $4(1.66)$ & \\
\hline & MANU 2 & SIT1088 & 777767777763771 & 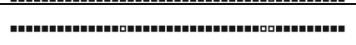 & $10(4.16)$ & \\
\hline & MANU3 & SIT1378 & 777777777770771 & 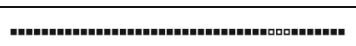 & $1(0.41)$ & \\
\hline \multirow{5}{*}{$\begin{array}{l}\text { Lineage 2 } \\
\text { (East } \\
\text { Asian) }\end{array}$} & \multirow[t]{5}{*}{ Beijing } & SIT255 & 000000000003671 & 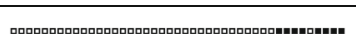 & $4(1.66)$ & \multirow[t]{5}{*}{$34(14.16)$} \\
\hline & & SIT260 & 000000000003171 & - & $1(0.41)$ & \\
\hline & & SIT1 & 000000000003771 & - & $27(11.25)$ & \\
\hline & & SIT1941 & 000000000003071 & Do & $1(0.41)$ & \\
\hline & & SIT269 & 000000000000771 & . & $1(0.41)$ & \\
\hline \multirow{18}{*}{$\begin{array}{l}\text { Lineage } 3 \\
\text { (East } \\
\text { African- } \\
\text { Indian) }\end{array}$} & \multirow{11}{*}{ CAS1_DEL } & SIT 2585 & 703763740003171 & & $2(0.83)$ & \multirow{18}{*}{$159(66.25)$} \\
\hline & & SIT26 & 703777740003771 & ...ponom......... & $29(12.08)$ & \\
\hline & & SIT 2694 & 703767740003571 & $\ldots$ & $1(0.41)$ & \\
\hline & & SIT309 & 703767740003171 & 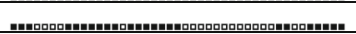 & $7(2.91)$ & \\
\hline & & SIT381 & 703777740003071 & 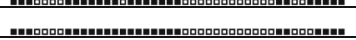 & $2(0.83)$ & \\
\hline & & SIT428 & 703777740003371 & 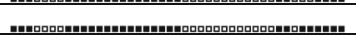 & $1(0.41)$ & \\
\hline & & SIT1401 & 703777740003671 & 10000000........... & $9(3.75)$ & \\
\hline & & SIT141 & 703767740003771 & . & $90(37.50)$ & \\
\hline & & SIT25 & 703777740003171 & & $2(0.83)$ & \\
\hline & & SIT1327 & 703637740003771 & 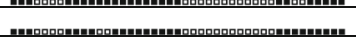 & $1(0.41)$ & \\
\hline & & SIT952 & 603777740003771 & & $1(0.41)$ & \\
\hline & \multirow[t]{6}{*}{ CAS } & SIT2591 & 703767740000000 & 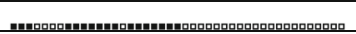 & $3(1.25)$ & \\
\hline & & SIT356 & 703777600001771 & 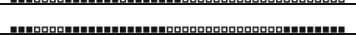 & $1(0.41)$ & \\
\hline & & SIT357 & 703777740000771 & C. & $1(0.41)$ & \\
\hline & & SIT1120 & 703760000000331 & & $3(1.25)$ & \\
\hline & & SIT864 & 703740000000760 & ה" & $2(0.83)$ & \\
\hline & & SIT142 & 703777700003771 & 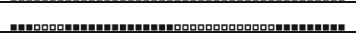 & $2(0.83)$ & \\
\hline & CAS2 & SIT288 & 700377740003771 & _. & $2(0.83)$ & \\
\hline \multirow{9}{*}{$\begin{array}{l}\text { Lineage } 4 \\
\text { (Euro- } \\
\text { American) }\end{array}$} & \multirow[t]{3}{*}{ T1 } & SIT53 & 777777777760771 & - & $3(1.25)$ & \multirow[t]{9}{*}{$17(7.08 \%)$} \\
\hline & & SIT118 & 777767777760771 & 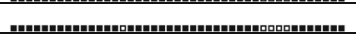 & $6(2.50)$ & \\
\hline & & SIT765 & 777760077760771 & (2) & $1(0.41)$ & \\
\hline & $\mathrm{T} 2$ & SIT2164 & 7777777777740731 & & $1(0.41)$ & \\
\hline & T5 & SIT44 & 777777757760771 & 2 & $1(0.41)$ & \\
\hline & LAM2 & SIT194 & 677737607760731 & 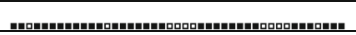 & $1(0.41)$ & \\
\hline & LAM9 & SIT42 & 777777607760771 & - & $1(0.41)$ & \\
\hline & $\mathrm{X} 1$ & SIT221 & 777766777760771 & & $2(0.83)$ & \\
\hline & H1 & SIT62 & 777777774020731 & 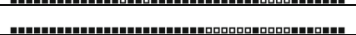 & $1(0.41)$ & \\
\hline
\end{tabular}

M.tuberculosis isolates into 11 SITs in patients from South India. In present study, the variation in clustering rate of isolates may be due to the inclusion of only MDR isolates of $M$. tuberculosis, difference in study period and/or geographical variation. The strains of shared type pattern (orphan) and without an assigned spoligotype (unique), made up 18.08\% (53/293) of the total isolates. The epidemiological significance of these strains needs further monitoring using advanced clinical and molecular tools with better discriminatory power.

In present study, four major lineages of M.tuberculosis were identified; East African-Indian lineage 3 (54.26\%) was found to be the most prevalent lineage followed by East Asian lineage 2 (11.60\%), Indo-Oceanic lineage 1 (10.23\%) and Euro-American lineage 4 (5.80\%) in North India. Considering the genotype patterns, current study confirms the occurrence of complex genetic diversity of MDR-TB in north India which ranges from ancient lineage (lineage 1) to modern TB lineages (lineage 2, 3 and 4) of $M$. tuberculosis. The higher clustering rate of the strains in modern lineages $(88.08 \%)$ as compared to ancient lineage (11.91\%) in our study indicates the substantial recent ongoing transmission of drug resistantTB in North India. The strains of East African-Indian lineage 3 have supposed to be linked with lower virulence, drug resistance and ability to spread [16]. Therefore the environmental and biological factors linked to enhanced levels of drug resistance and likely to expediting their expansion in particular geographical region need to be addressed.

Considering the spoligotyping patterns, the majority of the isolates in present study were clustered in CAS1_Del family $(n=148,50.51 \%)$ followed by Beijing $(n=33$, $11.26 \%)$. Similar to the present study, Sharaf-Eldin et al., [17] reported that the $M$. tuberculosis strains of CAS1_ Delhi lineage were more likely to develop drug resistance 
Table 4 Description of 15 shared types containing 32 isolates of M. tuberculosis that matched a pre-existing shared type pattern in the SITVIT2 database

\begin{tabular}{|c|c|c|c|}
\hline \multicolumn{2}{|r|}{ Spoligotype } & \multirow[t]{2}{*}{ SIT/ family } & \multirow[t]{2}{*}{ No. of isolates } \\
\hline Octal code & Pattern & & \\
\hline 777606777760771 & 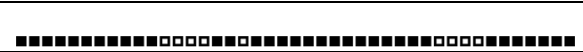 & Orphan/X1 & 1 \\
\hline 777777777743771 & ........................................ & $\begin{array}{l}\text { SIT2276/ } \\
\text { Unknown }\end{array}$ & 1 \\
\hline 777777777433771 & 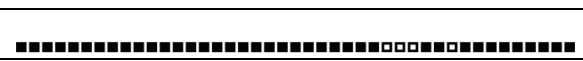 & Orphan/MANU1 & 1 \\
\hline 777767777413771 & 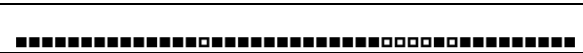 & Orphan /EAI5 & 1 \\
\hline 777767777413631 & 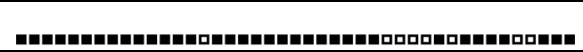 & Orphan /EAI5 & 4 \\
\hline 703775740003771 & ... & Orphan /CAS1 & 1 \\
\hline 703767740000771 & ... & Orphan/CAS & 1 \\
\hline 703767740000371 & 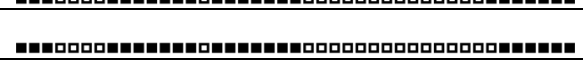 & Orphan/CAS & 1 \\
\hline 700367740003771 & 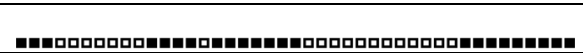 & Orphan / CAS2 & 10 \\
\hline 477777777773771 & . & $\begin{array}{l}\text { Orphan / } \\
\text { MANU1 }\end{array}$ & 1 \\
\hline 477747777413071 & 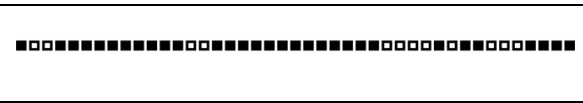 & $\begin{array}{l}\text { Orphan } \\
\text { /EAI3 IND }\end{array}$ & 1 \\
\hline 477767774000771 & 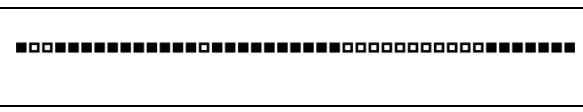 & $\begin{array}{l}\text { Orphan } \\
\text { /Unknown }\end{array}$ & 1 \\
\hline 777767777403671 & 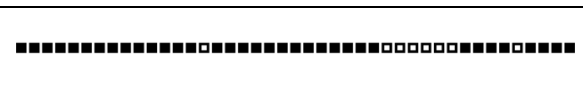 & $\begin{array}{l}\text { Orphan } \\
\text { /Unknown }\end{array}$ & 6 \\
\hline 777777740000000 & م & $\begin{array}{l}\text { Orphan } \\
\text { /Unknown }\end{array}$ & 1 \\
\hline 777777777400371 & |...................... & $\begin{array}{l}\text { Orphan } \\
\text { /Unknown }\end{array}$ & 1 \\
\hline
\end{tabular}

or MDR compared to those with other spoligotype patterns in Sudan. In present study, Beijing genotype; which is supposed to be widespread and considered as a predilection for the development of drug resistance in $M$. $t u$ berculosis strains was found as second most prevalent genotype in MDR strains in North India. Previously, Arora et al., [18] reported high proportion of Beijing (41.81\%) as compared to CAS (36.36\%) genotypes among MDR strains from paediatric TB patients from Delhi, India. Almeida et al., [4] also reported a high frequency of the Beijing strains (35\%) as compared to Delhi genotype (31\%) among MDR isolates recovered in and around Mumbai, India. Previously, it has been noted that the association between Beijing strains and MDR varies worldwide $[19,20]$. The difference between the findings of present study and earlier studies from India may be attributed to the variation in the predominant genotypes in study areas, difference in study duration and variation in sample size and/ or study designs. Recently, Desikan et al., [15] investigated the predominant circulating genotypes of $M$. tuberculosis in Bhopal, Central India and identified CAS1_DEL followed by EAI3_IND as the most predominant type.

In present study, SIT141 $(n=96 ; 32.76 \%)$ and SIT26 $(n=28 ; 9.55 \%)$ of CAS1_Del family followed by SIT1 ( $n=27 ; 9.21 \%)$ of Beijing family were found the predominant SITs among MDR-TB isolates in North India. Previously, the presence of SIT141/CAS1_Del has also been identified in strains from Delhi and different regions of the country $[4,18,21]$. The presence of SIT26/CAS1-Delhi has been mainly reported from countries of the Middle-East and Central Asia, or regions that have witnessed an important migration to or from the Indian sub-continent, e.g. Africa, East Asia, United States and Europe [22, 23]. Recently, Desikan et al., [15] reported the predominance of SIT26/CAS1_Del strains in central India. Basir et al., [13] also reported the predominance of SIT26/ CAS1_Del in isolates from Kashmir Valley, India. Arora et al. [18] reported SIT1/ Beijing and SIT26/CAS1-Delhi as predominant genotype among the XDR-TB isolates in and around the Delhi region of India. The predominance of CAS1-Delhi and 
Table 5 Spoligotypes of 21 isolates not identified in SITVIT2 database by a SIT number or clade and analysed by SpotClust tool

\begin{tabular}{|c|c|c|c|}
\hline Octal Code & $\begin{array}{l}\text { No. of } \\
\text { isolates }\end{array}$ & $\begin{array}{l}\text { Probable family using } \\
\text { SpotClust tool }\end{array}$ & Probability \\
\hline $\begin{array}{l}477767777400 \\
071\end{array}$ & 1 & EAI3 & 0.999 \\
\hline $\begin{array}{l}477767777403 \\
071\end{array}$ & 1 & EAI3 & 0.999 \\
\hline $\begin{array}{l}777677776001 \\
730\end{array}$ & 1 & EAI5 & 0.985 \\
\hline 007777777403600 & 1 & EAl5 & 0.997 \\
\hline $\begin{array}{l}373767777413 \\
731\end{array}$ & 1 & EAl5 & 0.996 \\
\hline $\begin{array}{l}477001777403 \\
771\end{array}$ & 1 & EAl5 & 0.999 \\
\hline $\begin{array}{l}477767777403 \\
771\end{array}$ & 1 & EAI5 & 0.993 \\
\hline $\begin{array}{l}703767777403 \\
671\end{array}$ & 3 & EAl5 & 0.990 \\
\hline $\begin{array}{l}777000777403 \\
771\end{array}$ & 1 & EAl5 & 0.993 \\
\hline $\begin{array}{l}501767500002 \\
660\end{array}$ & 1 & CAS & 0.999 \\
\hline $\begin{array}{l}700367700001 \\
671\end{array}$ & 1 & CAS & 0.999 \\
\hline $\begin{array}{l}701767740003 \\
771\end{array}$ & 1 & CAS & 0.999 \\
\hline $\begin{array}{l}703601740003 \\
731\end{array}$ & 1 & CAS & 0.999 \\
\hline $\begin{array}{l}703764000003 \\
771\end{array}$ & 1 & CAS & 0.999 \\
\hline $\begin{array}{l}703767600003 \\
771\end{array}$ & 1 & CAS & 0.999 \\
\hline $\begin{array}{l}703767740000 \\
671\end{array}$ & 1 & CAS & 0.999 \\
\hline $\begin{array}{l}555747777643 \\
771\end{array}$ & 1 & Family 33 & 0.999 \\
\hline $\begin{array}{l}557767777653 \\
771\end{array}$ & 1 & Family 33 & 0.999 \\
\hline $\begin{array}{l}777667777620 \\
000\end{array}$ & 1 & $\mathrm{~T} 2$ & 0.999 \\
\hline
\end{tabular}

Beijing strains among MDR-TB patients in this study and presence of these clades in other parts of the country $[5,12,13,24]$ underlines the rapid dissemination of these lineages across large geographical regions in India. In present study, Beijing clade is followed by ill-defined Manu (5.11\%), EAI3_IND clade (4.09\%), T (4.09\%), CAS (3.41\%), CAS2 $(0.68 \%)$, LAM $(0.68 \%), X(0.68 \%)$ and Haarlem $(0.34 \%)$ in decreasing order. These observations indicated the complex diversity of circulating M.tuberculosis strains among MDR - TB patients and reflect the occurrence of different transmission pathways for MDRTB in North India.
In present study, no statistically significant association was found between the occurrence of genotypic lineages of MDR-M.tuberculosis isolates and clinical or epidemiological features of the study population. Similar to the present study, Desikan et al., [15] also did not find any association between clustered isolates and demographic variables like age, and gender and treatment history of the TB patients in central India. Similarly, Niobe-Eyangoh et al., [25] did not find any significant association between genotypic families of M.tuberculosis complex isolates form pulmonary $\mathrm{TB}$ patients and patient characteristics (sex, age, and human immunodeficiency virus status) in Cameroon. However, Jiao et al., [26] investigated the strain diversity of $M$. tuberculosis isolates from pediatric cases and found that the prevalence rate of Beijing family strains were significantly higher $(P$ value $=0.029)$ in new cases $(91.0 \%)$ as compared to previously treated cases (69.6\%) among children in China. The explanation for the differences may be due to the geographical variation, difference in predominant genotypic lineage of $M$. tuberculosis, sample size and methodology of the study. Further attention is needed to understand the clinical, genetic and social correlations of the evolution of drug resistant M. tuberculosis strains in North India.

\section{Conclusions}

In conclusion, our study highlights that the MDR-TB in North India is caused due to heterogeneous groups predominated by CAS1_Delhi (SIT141 and 26) and Beijing (SIT1) lineages of $M$. tuberculosis. The higher presence of orphan and unique spoligotype patterns among MDR isolates in present study indicates high evolutionary pressure and clonal expansion of locally evolved strains in North India, which may have the potential to be a growing threat to public health. The result of this study emphasise the need of continuous surveillance of genetic diversity among drug resistant especially MDR and XDR-TB strains of $M$. tuberculosis to better understand the evaluation and transmission dynamics of drug resistant TB in India.

\section{Methods}

The study was carried out from January 2017 to January 2020 in the department of Microbiology and Molecular Biology, ICMR-National JALMA Institute for Leprosy and other Mycobacterial Diseases, India. All experiments and methods were performed in accordance with relevant guidelines and regulations. All the study protocols were approved by the Institutional Human Ethics Committee. 
Table 6 Distribution of MDR-M.tuberculosis isolates according to its genotypic lineages and clinical/epidemiological features of the patients

\begin{tabular}{|c|c|c|c|c|c|c|c|}
\hline \multirow[t]{2}{*}{ Variable } & \multirow[t]{2}{*}{ Category } & \multirow{2}{*}{$\begin{array}{l}\text { Total no. } \\
\text { of } \\
\text { isolates } \\
(n=240)\end{array}$} & \multicolumn{4}{|c|}{ No. of $M$. tuberculosis isolates in different genotypic lineages } & \multirow[t]{2}{*}{$p$-value } \\
\hline & & & Indo-Oceanic & East Asian & East African-Indian & Euro-American & \\
\hline \multirow[t]{2}{*}{ Gender } & Female & 86 & 15 & 12 & 54 & 5 & 0.366 \\
\hline & Male & 154 & 15 & 22 & 105 & 12 & \\
\hline \multirow[t]{3}{*}{ Age } & $18-35$ & 163 & 20 & 23 & 109 & 11 & 0.578 \\
\hline & $36-55$ & 54 & 9 & 6 & 36 & 3 & \\
\hline & Above 55 & 23 & 1 & 5 & 14 & 3 & \\
\hline \multirow[t]{2}{*}{ Living conditions } & Rural & 95 & 11 & 13 & 63 & 7 & 0.987 \\
\hline & Urban & 145 & 19 & 21 & 96 & 10 & \\
\hline \multirow[t]{2}{*}{ Weight loss } & No & 39 & 5 & 5 & 26 & 3 & 0.993 \\
\hline & Yes & 201 & 25 & 29 & 133 & 14 & \\
\hline \multirow[t]{2}{*}{ Previous history of TB treatment } & No & 83 & 12 & 15 & 49 & 7 & 0.379 \\
\hline & Yes & 157 & 18 & 19 & 110 & 10 & \\
\hline
\end{tabular}

\section{Mycobacterium tuberculosis isolates}

During the period of 2017-2019, a total of 293 MDR isolates were recovered from sputum samples of suspected MDR-TB cases and included in this study. After appropriate counseling and written informed consent; detailed demographic information, clinical history and physical characteristics of all the study participants were recorded. The sputum samples of the study participants were processed for the isolation of mycobacteria on Lowenstein-Jensen medium as per the method described by Raizada et al., [27]. The species level identification of the isolates was performed using standard biochemical tests viz. nitrate reduction, catalase activity at $68{ }^{\circ} \mathrm{C}$, Tween 80 hydrolysis, aryl sulphatase test and growth on Mac'Conkeys medium as per CDC manual given by Vestal [28]. The drug susceptibility patterns of M.tuberculosis isolates were studied against first line anti-TB drugs (rifampicin, isoniazid, ethambutol and streptomycin) using standard minimum inhibitory concentration method on LJ-medium as per the guideline of revised national tuberculosis control program, India. All the microbiological tests were performed in Biosafety level-3 (BSL-3) laboratory, Department of Microbiology and Molecular Biology, NJIL\&OMD, Agra.

\section{DNA extraction}

DNA was extracted from the log phase growth of $M$. tuberculosis isolates using the physical- chemical and enzymatic method [29]. Briefly, about 2 loopful growth of M. tuberculosis was suspended in $400 \mu \mathrm{l}$ of TE buffer and heated for $15 \mathrm{~min}$ at $95^{\circ} \mathrm{C}$ followed by immediate chilling in ice for $15 \mathrm{~min}$. The step was repeated thrice. To this $40 \mu \mathrm{l}$ lysozyme $(20 \mu \mathrm{g} / \mathrm{ml})$ was added, mixed gently and incubated for $2 \mathrm{~h}$ at $37^{\circ} \mathrm{C}$. After this, $56 \mu \mathrm{l}$ of $10 \%$ SDS was added and mixed gently by inverting the tubes 5-6 times followed by addition of $5.0 \mu \mathrm{l}$ of

Table 7 Association between clustered and un-clustered MDR-M.tuberculosis isolates with clinical/epidemiological features of the patients

\begin{tabular}{|c|c|c|c|c|c|}
\hline Variable & Category & Total no. of isolates $(n=293)$ & Clustered Isolates (\%) & Un-clustered Isolates (\%) & $p$-value \\
\hline \multirow[t]{2}{*}{ Gender } & Female & 105 & $86(81.90)$ & 19(18.09) & 0.998 \\
\hline & Male & 188 & $154(81.91)$ & $34(18.08)$ & \\
\hline \multirow[t]{3}{*}{ Age } & $18-35$ & 198 & $163(82.32)$ & $35(17.67)$ & 0.776 \\
\hline & $36-55$ & 68 & $54(79.41)$ & $14(20.58)$ & \\
\hline & Above 55 & 27 & $23(85.18)$ & $4(14.81)$ & \\
\hline \multirow[t]{2}{*}{ Living conditions } & Rural & 110 & $95(86.36)$ & $15(13.63)$ & 0.124 \\
\hline & Urban & 183 & $145(79.23)$ & $38(20.76)$ & \\
\hline \multirow[t]{2}{*}{ Weight loss } & No & 45 & $39(86.66)$ & $6(13.33)$ & 0.367 \\
\hline & Yes & 248 & $201(81.04)$ & $47(18.95)$ & \\
\hline \multirow[t]{2}{*}{ Previous history of TB treatment } & No & 99 & $83(83.83)$ & $16(16.16)$ & 0.540 \\
\hline & Yes & 194 & 157 (80.92) & $37(19.07)$ & \\
\hline
\end{tabular}


Table 8 Association between the occurrence of most predominant genotypic lineage (East African-Indian) and clinical/ epidemiological features of the patients

\begin{tabular}{|c|c|c|c|c|c|}
\hline Variable & Category & Total no. of isolates $(n=240)$ & $\begin{array}{l}\text { East African-Indian } \\
\text { Isolates }(n=159)(\%)\end{array}$ & $\begin{array}{l}\text { Others genotypic lineage } \\
(n=81)(\%)\end{array}$ & $p$-value \\
\hline \multirow[t]{2}{*}{ Gender } & Female & 86 & $54(33.96)$ & $32(39.50)$ & 0.397 \\
\hline & Male & 154 & $105(66.03)$ & $49(60.49)$ & \\
\hline \multirow[t]{3}{*}{ Age } & $18-35$ & 163 & $109(68.55)$ & $54(66.66)$ & 0.847 \\
\hline & $36-55$ & 54 & $36(22.64)$ & $18(22.22)$ & \\
\hline & Above 55 & 23 & $14(8.80)$ & $9(11.11)$ & \\
\hline \multirow[t]{2}{*}{ Living conditions } & Rural & 95 & $63(39.62)$ & $32(39.50)$ & 0.986 \\
\hline & Urban & 145 & $96(60.37)$ & $49(60.49)$ & \\
\hline \multirow[t]{2}{*}{ Weight loss } & No & 39 & $26(16.35)$ & $13(16.04)$ & 0.952 \\
\hline & Yes & 201 & $133(83.64)$ & $68(83.95)$ & \\
\hline \multirow[t]{2}{*}{ Previous history of TB treatment } & No & 83 & $49(30.81)$ & $34(41.97)$ & 0.0857 \\
\hline & Yes & 157 & $110(69.18)$ & $47(58.02)$ & \\
\hline
\end{tabular}

proteinase $\mathrm{K}(10 \mathrm{mg} / \mathrm{ml})$ and mixed well using vortex. Mixture was incubated at $65^{\circ} \mathrm{C}$ for $30 \mathrm{~min}$. After incubation, $80 \mu \mathrm{l}$ of $5 \mathrm{M} \mathrm{NaCl}$ and $64 \mu \mathrm{l}$ of pre-warmed CTAB / $\mathrm{NaCl}$ solution was added and milky tube content was mixed well and incubated at $65^{\circ} \mathrm{C}$ for $30 \mathrm{~min}$. Equal volume of freshly prepared chloroform - isoamyl alcohol (24:1) mixture was added and vortexed for mixing and centrifuged at $10000 \mathrm{rpm}$ for $5 \mathrm{~min}$. After centrifugation, three layers became visible; upper (aqueous) layer (about $300 \mu \mathrm{l}$ ) was transferred into a new sterile eppendrof tube. To the aqueous layer, 0.7 volume of iso-propanol alcohal $(180 \mu \mathrm{l})$ was added and gently mixed and incubated at $-20{ }^{\circ} \mathrm{C}$ overnight allowing DNA precipitation. Next day the solution was centrifuged at $10000 \mathrm{rpm}$ for $15 \mathrm{~min}$, supernatant was discarded and sediment was washed with $150 \mu \mathrm{l}$ of $70 \%$ chilled ethanol by centrifugation at $10000 \mathrm{rpm}$ for $5 \mathrm{~min}$. The supernatant was carefully discarded without disturbing the pellet. The washing step was repeated, the tube was allowed to air dry. Dried pellet was re-suspended in $30 \mu \mathrm{l}$ of TE buffer and stored at $-20{ }^{\circ} \mathrm{C}$ for further use in spoligotyping.

\section{Spoligotyping and analysis of patterns}

Spoligotyping was carried out by amplifying the whole DR region using the commercially available kit (Mapmygenome, Hyderabad) as per the method previously described by Sharma et al., [9]. Briefly, the extracted genomic DNA of M.tuberculosis isolates was subjected to PCR to amplify direct repeats (DR region) and interspersed known spacers region using primers designated as DRa and DRb (Mapmygenome, Hyderabad). The PCR product was hybridized to 43 covalently bound oligonucleotides derived from the spacer sequence of $M$. tuberculosis $\mathrm{H} 37 \mathrm{Rv}$ and $M$. bovis BCG. Hybridization signals were recorded by enhanced chemiluminescence detection system by exposing ECL-Hyper film (Amersham, GE Health Care). Distilled water was used as negative control and H37Rv and M.bovis BCG were used as positive controls. The presence and absence of spacer oligonucleotides were documented in the form of binary code that was converted into octal code and was compared with the international Database SITV IT WEB2. Spoligo patterns not found in SITVIT WEB2 were analyzed using "Spotclust".

\section{Association of spoligotype lineages and epidemiologic characteristics of the patient's}

The association between demographic information, clinical / epidemiological data of the patients and spoligotyping results of MDR-M.tuberculosis isolates were analysed. For the comparison of categorical variables, significance testing was performed by $\chi^{2}$ test by 2 -sided Fisher exact test as appropriate. The criterion for significance was set at $P<0.05$ based on a two-sided test. Collected data were computerized using Excel, cleaned, and entered to be analyzed using STATA software.

\section{Abbreviations \\ M.tuberculosis: Mycobacterium tuberculosis; MDR: Multidrug-resistant: \\ SIT: Spoligotype international types; TB: Tuberculosis; XDR: Extensively drug- resistant; WHO: World Health Organization}

\section{Acknowledgments}

The authors are thankful to the study participants for their cooperation in providing the clinical samples and necessary socio-demographic information in the study.

Authors' contributions

SS, AY and SK collected, cultured and identified the bacterial isolates, performed DNA extraction and genotyping. RY and DKS participated in data analyses and writing of the manuscript. AVS and DSC conceived the study, analyse the data and wrote the manuscript. All authors read and approved the final version of the manuscript. 


\section{Funding}

The support of this work by financial support (EMR/2016/003648) received from Department of Science and Technology, New Delhi is gratefully acknowledged. Dr. Rajbala Yadav received fellowship from Woman Scientist Award (WOS-A) Scheme, Department of Science and Technology, New Delhi.

\section{Availability of data and materials}

The datasets used and analysed in present study are available from the corresponding author on reasonable request.

\section{Declarations}

\section{Ethics approval and consent to participate}

All experiments and methods were performed in accordance with relevant guidelines and regulations. The experimental protocols of the study were approved by the Human Ethics Committee, ICMR- National JALMA Institute for leprosy and Other Mycobacterial Diseases, Agra, India. The written informed consent was obtained from all the study participants, before collection of clinical samples and personalized information.

\section{Consent for publication}

Not applicable.

\section{Competing interests}

The authors declare that they have no competing interests.

Received: 7 September 2020 Accepted: 25 March 2021

Published online: 21 April 2021

\section{References}

1. WHO. Global Tuberculosis Report 2019. Geneva: WHO; 2019. Available from: https://www.who.int/tb/publications/global_report/en/ (Accessed on 5.09.2020)

2. Ministry of Health and Family Welfare Government of India. Report of the first national anti-tuberculosis drug resistance survey: India 2014-16, 2018. https://tbcindia.gov.in/showfile.php?lid=3315 (Accessed on 5.09.2020).

3. Mistry NF, lyer AM, D'souza DT, Taylor GM, Young DB, Antia NH. Spoligotyping of Mycobacterium tuberculosis isolates from multiple-drugresistant tuberculosis patients from Bombay, India. J Clin Microbiol. 2002; 40(7):2677-80. https://doi.org/10.1128/JCM.40.7.2677-2680.2002.

4. Almeida D, Rodriques C, Ashavid TF, Lalvani A, Udwadia ZF, Mehta A. High incidence of the Beijing genotype among multi-drug resistant isolates of Mycobacterium tuberculosis in a tertiary care Centre in Mumbai, India. Clin Infect Dis. 2005;40(6):881-6. https://doi.org/10.1086/427940.

5. Chawla K, Kumar A, Shenoy VP, Chauhan DS, Sharma P. Genetic diversity of Mycobacterium tuberculosis in south coastal Karnataka, India, using spoligotyping. Indian J Med Res. 2018;147(3):278-86. https://doi.org/10.41 03/ijmr.IJMR_2026_16.

6. Prakash R, Gupta R, Sharma P, Jain S, Chauhan DS, Katoch VM, et al. Genotypic diversity of Mycobacterium tuberculosis isolates from north-central Indian population. Pathog Glob Health. 2019;113(1):39-48. https://doi.org/1 0.1080/20477724.2019.1583881.

7. Kamerbeek J, Schouls L, Kolk A, van Agterveld M, van Soolingen D, Kuijper $\mathrm{S}$, et al. Simultaneous detection and strain differentiation of Mycobacterium tuberculosis for diagnosis and epidemiology. J Clin Microbiol. 1997;35(4): 907-14. https://doi.org/10.1128/JCM.35.4.907-914.1997.

8. Gagneux S, Small PM. Global phylogeography of Mycobacterium tuberculosis and implications for tuberculosis product development. Lancet Infect Dis. 2007;7(5):328-37. https://doi.org/10.1016/S1473-3099(07)70108-1.

9. Sharma P, Chauhan DS, Upadhyay P, Faujdar J, Lavania M, Sachan S, et al. Molecular typing of Mycobacterium tuberculosis isolates from a rural area of Kanpur by spoligotyping and mycobacterial interspersed repetitive units (MIRUs) typing. Infect Genet Evol. 2008;8(5):621-6. https://doi.org/10.1016/j. meegid.2008.05.002.

10. Varma-Basil M, Nair D. Molecular epidemiology of tuberculosis: opportunities \& challenges in disease control. Indian J Med Res. 2017;146(1): 11-4. https://doi.org/10.4103/ijmr.IJMR_941_17.

11. Lobie TA, Woldeamanuel $Y$, Asrat D, Beyene D, Bjoras M, Aseffa A. Genetic diversity and drug resistance pattern of Mycobacterium tuberculosis strains isolated from pulmonary tuberculosis patients in the Benishangul Gumuz region and its surroundings, Northwest Ethiopia. PLoS One. 2020;15(4): e0231320. https://doi.org/10.1371/journal.pone.0231320.
12. Devi KR, Bhutia R, Bhowmick S, Mukherjee K, Mahanta J, Narain K. Genetic diversity of Mycobacterium tuberculosis isolates from Assam, India: dominance of Beijing family and discovery of two new clades related to CAS1_Delhi and EAl family based on Spoligotyping and MIRU-VNTR typing. PLoS One. 2015; 10(12):e0145860. https://doi.org/10.1371/journal.pone.0145860.

13. Bashir G, Wani T, Sharma P, Katoch VM, Lone R, Shah A, et al. Predominance of central Asian and European families among mycobacterium tuberculosis isolates in Kashmir Valley, India Indian. J Tuberc. 2017;64(4):302-8. https:// doi.org/10.1016/j.jitb.2017.05.004

14. Diriba B, Berkessa T, Mamo G, Tedla Y, Ameni G. Spoligotyping of multidrug-resistant Mycobacterium tuberculosis isolates in Ethiopia. Int J Tuberc Lung Dis. 2013;17(2):246-50. https://doi.org/10.5588/ijtld.12.0195.

15. Desikan P, Chauhan D, Sharma P, Panwalkar N, Chourey M, Patidar M, et al. Genetic diversity of Mycobacterium tuberculosis isolates from Central India. IndianJ Med Res. 2016;143(4):481-6. https://doi.org/10.4103/0971-5916.184287.

16. Albanna AS, Reed MB, Kotar KV, Fallow A, McIntosh FA, Behr MA, et al. Reduced transmissibility of east African Indian strains of Mycobacterium tuberculosis. PLoS One. 2011;6(9):e25075. https://doi.org/10.1371/journal. pone. 0025075 .

17. Sharaf Eldin GS, Fadl-Elmula I, Ali MS, Ali AB, Salih AL, Mallard K, et al. Tuberculosis in Sudan: a study of Mycobacterium tuberculosis strain genotype and susceptibility to anti-tuberculosis drugs. BMC Infect Dis. 2011; 11(1):219. https://doi.org/10.1186/1471-2334-11-219.

18. Arora J, Sidiq Z, Sharma S, Singhal R, Bhalla M, Couvin D, et al. Phylogenetic associations with drug resistance of pulmonary Mycobacterium tuberculosis isolates in a pediatric population. Int J Tuberc Lung Dis. 2014;18(10):117217. https://doi.org/10.5588/ijtld.14.0173.

19. Anh DD, Borgdorff MW, Van LN, Lan NT, van Gorkom T, Kremer K, et al. Mycobacterium tuberculosis Beijing genotype emerging in Vietnam. Emerg Infect Dis. 2000;6(3):302-5. https://doi.org/10.3201/eid0603.000312.

20. van Soolingen D, Qian L, de Haas PE, Douglas JT, Traore H, Portaels F, et al. Predominance of a single genotype of Mycobacterium tuberculosis in countries of East Asia. J Clin Microbiol. 1995;33(12):3234-8. https://doi.org/1 0.1128/JCM.33.12.3234-3238.1995.

21. Singh UB, Suresh N, Bhanu NV, Arora J, Pant H, Sinha S, et al. Predominant tuberculosis spoligotypes, Delhi, India. Emerg Infect Dis. 2004;10(6):1138-42. https://doi.org/10.3201/eid1006.030575.

22. Brudey K, Driscoll JR, Rigouts L, Prodinger WM, Gori A, Al-Hajoj SA, et al. Mycobacterium tuberculosis complex genetic diversity: mining the fourth international spoligotyping database (SpolDB4) for classification, population genetics and epidemiology. BMC Microbiol. 2006;6:23.

23. Demay C, Liens B, Burguiere T, Hill V, Couvin D, Millet J, et al. SITVTWWEB-a publicly available international multimarker database for studying Mycobacterium tuberculosis genetic diversity and molecular epidemiology. Infect Genet Evol. 2012;12(4):755-66. https://doi.org/10.1016/.j.meegid.2012.02.004

24. Chatterjee A, D'Souza D, Vira T, Bamne A, Ambe GT, Nicol MP, et al. Strains of Mycobacterium tuberculosis from western Maharashtra, India, exhibit a high degree of diversity and strain-specific associations with drug resistance, cavitary disease, and treatment failure. J Clin Microbiol. 2010; 48(10):3593-9. https://doi.org/10.1128/JCM.00430-10.

25. Niobe-Eyangoh SN, Kuaban C, Sorlin P, Cunin P, Thonnon J, Sola C, et al. Genetic biodiversity of Mycobacterium tuberculosis complex strains from patients with pulmonary tuberculosis in Cameroon. J Clin Microbiol. 2003; 41(6):2547-53. https://doi.org/10.1128/JCM.41.6.2547-2553.2003.

26. Jiao W, Liu Z, Han R, Zhao X, Dong F, Dong H, et al. A country-wide study of spoligotype and drug resistance characteristics of Mycobacterium tuberculosis isolates from children in China. PLoS One. 2013;8:e84315.

27. Raizada N, Sachdeva KS, Sreenivas A, Vadera B, Gupta RS, Parmar M, et al. Feasibility of decentralised deployment of Xpert MTB/RIF test at lower level of health system in India. PLoS One. 2014;9(2):e89301. https://doi.org/10.13 71/journal.pone.0089301.

28. Vestal AL. Procedures of isolation and identification of mycobacteria. U.S. Department of Health, education, and welfare publication no. (CDC) 778230, p. 65-98: Centers for disease control, Atlanta, Ga; 1977.

29. van Soolingen D, de Haas PE, Hermans PW, van Embden JD. DNA fingerprinting of Mycobacterium tuberculosis. Methods Enzymol. 1994;235; 196-205. https://doi.org/10.1016/0076-6879(94)35141-4.

\section{Publisher's Note}

Springer Nature remains neutral with regard to jurisdictional claims in published maps and institutional affiliations. 